International Journal of Biology, Pharmacy and Allied Sciences (IJBPAS) 'A Bridge Betusen Caboratory and QRendo'

WwW.iibpas.com

\title{
IN VIVO STUDIES OF IMMUNOGLOBULINS AND SERUM PROTEINS IN TOXOPLASMOSIS PATIENTS IN PRESENCE OF NANO PARTICLE (ZNO) INTERACTION
}

MOHAMMED TORKI HAMMOOD* ${ }^{*}$ Dr. ALAPATI KRISHNA SATYA College of science, M.Sc Nano Biotechnology, Department of Biotechnology, Acharya Nagarjuna University, Guntur, Andhra Pradesh, India

*Corresponding Author: mohammedaltorki5@gmail.com

Received 27 ${ }^{\text {th }}$ Aug. 2018; Revised $20^{\text {th }}$ Sept. 2018; Accepted $28^{\text {th }}$ Oct. 2018; Available online $1^{\text {st }}$ Feb. 2019 https://doi.org/10.31032/IJBPAS/2019/8.2.4631

\begin{abstract}
Infection caused by Toxoplasma gondii, toxoplasmosis, is the common zoo noses in India along with other tropical countries of world. People with a typical immune system generally show signs of improvement with no treatment. Treatment is, in any case, regularly required for people with immune lack or for women who are pregnant. Toxoplasmosis can be hazardous for immune compromised patients, ordinarily because of reactivation of constant infection. In the current research examination a retrospective analysis of the clinical states of toxoplasmosis patients went to at Government Fever Hospital (GFH), Gorantla, Guntur, India with sample estimate 25 women patients and 8 of these were pregnant. Auxiliary information were acquired from patients' records; the factors that were gathered included sex, age, signs and side effects, pregnancy circumstance, ophthalmic condition, $\operatorname{IgA}$, IgM and $\operatorname{IgG}$ hostile to toxoplasmosis titers, and treatment conspire. A non-huge increment in the movement and particular action of protease in the sera of women contaminated with toxoplasmosis were seen in contrast with their qualities in the solid $(\mathrm{p}>0.05)$. While a non-noteworthy decline in absolute protein esteems was accounted for. The aftereffects of impact of nanoparticles demonstrated a decline in the level of the compound within the sight of Zinc nanoparticles by $52.24 \%$, while the outcomes demonstrated that hindrance of $\mathrm{ZnO}$ nanoparticles nanoparticles was lesser and 51.37\%. The outcomes demonstrated that $\operatorname{IgA}, \operatorname{IgG}$, and $\operatorname{IgM}$ levels were diminished within the sight Zinc nanoparticles.
\end{abstract}

Keywords: Toxoplasmosis, Human samples, Nanoparticles, Ig, interaction study 


\section{INTRODUCTION}

Nanoparticles, due to their size, shape and surface chemistry are prone to interception by different defense components following entry into the body. For macrophage avoidance of nanoparticles several strategies that suppress the opsonisation processes can be undertaken. Thus, nanoparticle surface modification or coating with natural occurring complement inhibitors yield stealth or macrophageavoiding nanoparticles [1]. Toxoplasmosis, one of most basic existing zoonoses, is caused by Toxoplasma gondii [2], a protozoan that has a heteroxenous life cycle and can contaminate different well evolved creature and fowl species through various transmission pathways, however cats are the authoritative host. It has a cosmopolitan conveyance; serological studies have exhibited a huge range, influencing numerous nations, geographic regions and ethnic gatherings. Although the definitive diagnosis of toxoplasma infection and toxoplasmosis is established by demonstration of the tachyzoite form of the parasite either histologically or by isolation procedures, improvements in serologic diagnosis now usually obviate the need for biopsy and isolation studies, except in some patients with congenital toxoplasma infection and when disease occurs in immune compromised patients [3]. Nanomedicine is characterized as use of nanotechnology for treatment, checking, counteractive action, and control of biological illnesses. To apply nanomedicine, the exact targets (cells as well as receptors) particular to the clinical infection ought to be recognized and the appropriate nanoparticles for conveyance system to limit the symptoms of the first medication ought to be chosen [4]. Nanoparticles (NPs) are a tool for specifically targeting drugs or diagnostics to selected tissues or cell types. Their use in toxoplasmosis research and therapy is of special interest as well as to overcome the immunity barrier. At least in theory, they are a tool to optimize pharmacological data such as drug release, tissue specificity and even cell specificity [5]. Nanomaterials include Zinc, gold, platinum, and magnetic NPs, quantum dots, liposomes, nanospheres, carbon nanorods, nanotubes, and others. Zinc, Ag and gold NPs were the commonest elements used, and constituted the majority of publications in the last 10 years. In the finding of other parasitic sicknesses, a similar idea of NPs conjugation with the parasite biomarkers was utilized. In toxoplasmosis, the utilization of particular agglutination of antigen-covered gold NPs in the recognition of the relating immune response gave attractive concurrence with ELISA results [6]. An immunomagnetic 
dab ELISA strategy using T. gondii $\mathrm{IgG}$ polyclonal antibodies covered with attractive NPs to catch circling surface antigen 1 gave preferred outcomes over sandwich ELISA [7]. As sole treatment, targeting infected macrophages with NPs is a valuable and validated strategy for treatment of Toxoplasmosis. Zinc nanoparticle evaluated singly/ combined for in vivo treatment of toxoplasmosis in experimental animals [8]. The study of intrigue includes the interactions among nanoparticles and the segments of the immune system. Nanoparticles can be intended to either stay away from immune system recognition or particularly improve or repress the immune reactions [9]. At the point when nanoparticles enter the body, their interactions with cells are relatively unavoidable [10]. An interaction between a nanoparticle and the immune system is viewed as alluring when it might prompt different useful medicinal applications, for example, immunizations, conveyance of medications, antigens or therapeutics for provocative and autoimmune clutters [11]. This investigation plans to assess the effect of some immune proteins by the presence of laboratory made Zinc $(\mathrm{ZnO})$ nanoparticles in sera of toxoplasmosis patients.

\section{MATERIALS AND METHOD}

2.1 Zinc Oxide nanoparticle

preparation: In the present study, $\mathrm{ZnO}$ nanoparticles were synthesized by a simple precipitation method proposed by Surabhi Siva Kumar et al (2013) [12]. Zinc sulfate heptahydrate and sodium hydroxide were used as precursors to formulate $\mathrm{ZnO}$ nanostructures. The powder obtained from the above method was calcined at different temperatures such as $400^{\circ} \mathrm{C}, 600^{\circ} \mathrm{C}$ and $800^{\circ} \mathrm{C}$ for $2 \mathrm{~h}$.

2.2 Sample Collection: In this casecontrol study, 17 to 26 year old 25 women patients including 8 pregnant women with no clinical complications had participated. Blood samples were collected in Government fever hospital, Guntur, India, with the prior permission of authorities and informed consent was taken from every patient for the motivations behind the present examination, January 2017 to November 2018. Healthy women around 21 age were taken as a control and were included in this study. Information sheets were prepared, and demographic questionnaires were taken from the participants. Then, $2.5 \mathrm{ml}$ of whole blood were collected, and sera were tested for the proteins using standard procedure. $2.5 \mathrm{ml}$ of venous blood was collected from each sample, and placed in a plane tube, and left (20 minutes) at room temperature to clot, then centrifuged at $2000 \mathrm{rpm}$ for 15 minutes. Serum that obtained was stored at $\left(-20^{\circ} \mathrm{C}\right)$ until they will be used. The activity of serum protease was determined 
using casein as substrate according to assay method, and the specific activity of protease was expressed as $\mu \mathrm{mol} / \mathrm{g}$ of protein. Serum total protein was determined using colorimetric method of Biurite. IgA, IgG and IgM were measured using ELISA method.

\subsection{UV-Visible Studies: The UV-Vis} spectral analysis was carried out for the synthesized Zn NPs in the range of 300$800 \mathrm{~nm}$ in a spectrophotometer (Unicam UV5-220), using a quartz cuvette with water as the reference, one hour after preparation.

2.5 SEM Analysis: The prepared samples were characterized by scanning electron microscopy (SEM). The morphology, crystallite size, and optical properties of $\mathrm{ZnO}$ nanostructures were investigated, and an attempt was made to correlate the optical properties of $\mathrm{ZnO}$ with morphology and crystallite size.

\subsection{Characterization by SEM-EDX:}

The compounds were characterized for their structure and morphology by SEM. SEM images of the samples were taken using a Philips XL 30 ESEM scanning electron microscope (FEI-Philips Company, Hillsboro) Equipped with EDX analyzer

2.7 Statistical analysis: The data collected were analyzed with SPSS software version 11. The data were expressed as mean $\pm \mathrm{SD}$.
2.8 Ethics statement: Written consent was obtained from each patient and ethics approval was obtained from the Ethical Committee of the medical centre

2.9 Immunological study: Interferon gamma (INF $\gamma$ ) was measured in the sera of patients treated with both ZnO NPs stored at $-20{ }^{\circ} \mathrm{C}$ using an ELISA kit (Interferon Gamma Elisa kit -Sigma Aldrich RAB0520). The assay was carried out as recommended by the manufacturer. The quantitative estimation of immunoglobulins (IgG, IgA, 1gM) was completed by spiral immune diffusion strategy of Mancini. The nanoparticles used in this study consisted of $\mathrm{ZnO}$ nanoparticles colloidal solution. To come nearer to in vivo conditions and to make it simple to watch an impact, the way of life should work for not less than 3 days to permit a few cycles of multiplication.

\section{RESULTS AND DISCUSSION}

As part of our research programme, we synthesize nanoparticles with enhanced particle properties using chemical routes that help in controlling the surface energy. The functionalized particles were characterized by the following techniques.

\subsection{UV Vis analysis of ZnNPs : Figure} 1 shows the UV-Vis absorption spectra of synthesized ZnNPs at different calcinations temperatures $\left(400,600,800^{\circ} \mathrm{C}\right)$. The absorption peak of ZnNPs were observed at $366,366.8 \& 367.0 \mathrm{~nm}$ at calcinated temperature of $400,600,800 \mathrm{oC}$ 
respectively. As temperature increases, the peak absorbance wavelength become red shifted due to decreasing quantum confinement with increasing particle size. These peaks are due to electronic transition from deep level of valence band to conduction band. The UV-Vis absorption peak variation among the ZnNPs are due to the difference in their size and shape, which results due to a variety of precursors and calcination temperature [13].

\subsection{SEM-EDX analysis: The SEM} images of the samples are shown in Figure 2a. The morphologies of $\mathrm{ZnO}$ are changed with calcination temperature. The samples calcined at $400^{\circ} \mathrm{C}$ and $600^{\circ} \mathrm{C}$ are nanoflakes which are turned to particles when calcined at $800^{\circ} \mathrm{C}$. The SEM images of $\mathrm{ZnO}$ samples show that the agglomerations of particles are much less in this method of preparation. High-resolution SEM images (3600x, 3800x, 3700x) of $\mathrm{ZnO}$ calcined at $400^{\circ} \mathrm{C}, 600^{\circ} \mathrm{C}$ and $800^{\circ} \mathrm{C}$ (Figure 2) show the presence of spherical shaped nanoparticles. The energy dispersive spectra of the samples obtained from the SEM-EDS analysis (Figure 3) clearly show that the sample prepared by the above route has pure $\mathrm{ZnO}$ phases. From the SEM study average particle size is found as $42 \mathrm{~nm}, 37 \mathrm{~nm}$ and $32 \mathrm{~nm}$ at 400 , 600 and $800^{\circ} \mathrm{C}$ temperature.

\section{Nanoparticles therapy to Humans affected with Toxoplasmosis:}

During the pathogenic study period, 25 patients had attended at the toxoplasmosis outpatient service of GFH clinic. Among those, 16 presented acute infection by Toxoplasma gondii based on serology. Most patients were non pregnant women $(64 \%$ - 16/25) and four are pregnant women (50\%-4/8) attended at the service. The mean age of all patients was 20.9 years old (median= 22.5; $\mathrm{SD}=11.67)$. While in the pregnant group it was significantly higher $(t=-6.34 ; \mathrm{p}<0.05)$. Many pregnant women referred to our service were positive for anti-toxoplasmosis $\operatorname{IgM}$ and negative for $\operatorname{IgG}$, which configures a previous infection, but not necessarily a recent one. Considering that toxoplasmosis serology is a standard procedure in prenatal care in India, this fact reveals that some services involved in pregnancy assistance are not able to interpret a serological test properly, leading to a wrong or a doubtful diagnosis (Silva et al ., 2008). The mean serum immunoglobulins in patients and controls are shown in Table 1.

3.2. Immunological results: The mean concentrations of INF $\gamma$ in all subgroups are demonstratedin Table 2. In general, all infected patients receiving NPs showed increased level of INF $\gamma$. This was more pronounced in patients treated by ZnNPs. 
Concentrations were shown in table 2 and Figure 3.

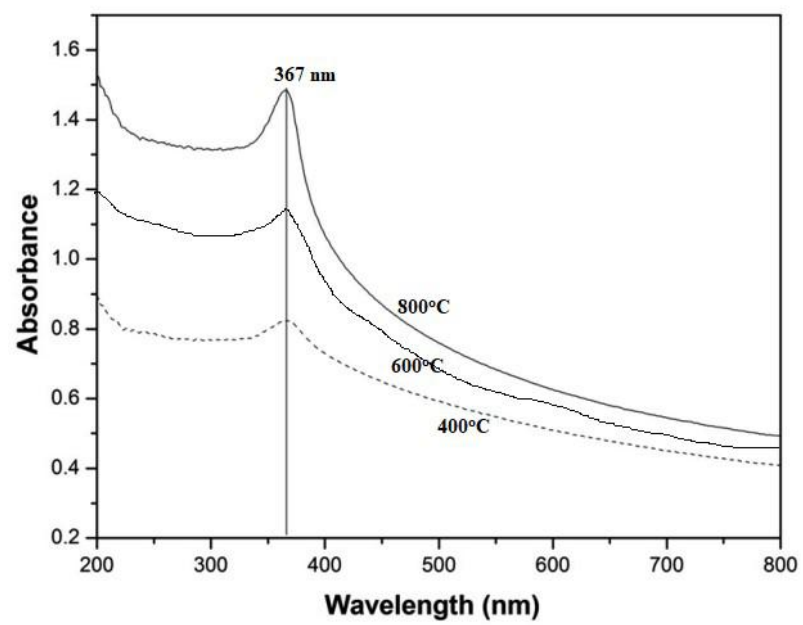

Figure 1: UV-Vis absorption spectra of ZnNPs at different temperatures

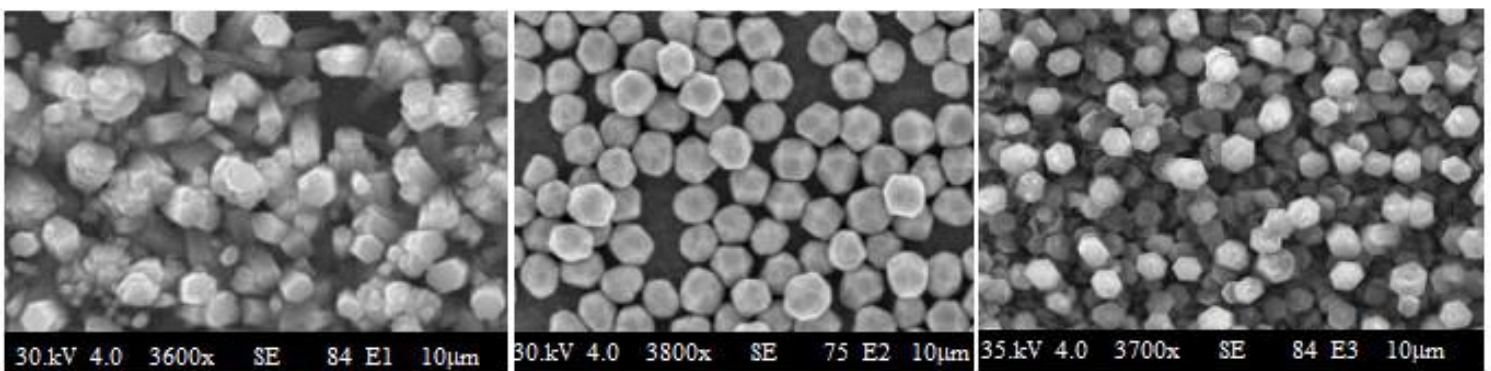

Figure 2a: SEM image of ZnNPs calcined at temperature $400{ }^{\circ} \mathrm{C}, 600^{\circ} \mathrm{C}$ and $800^{\circ} \mathrm{C}$

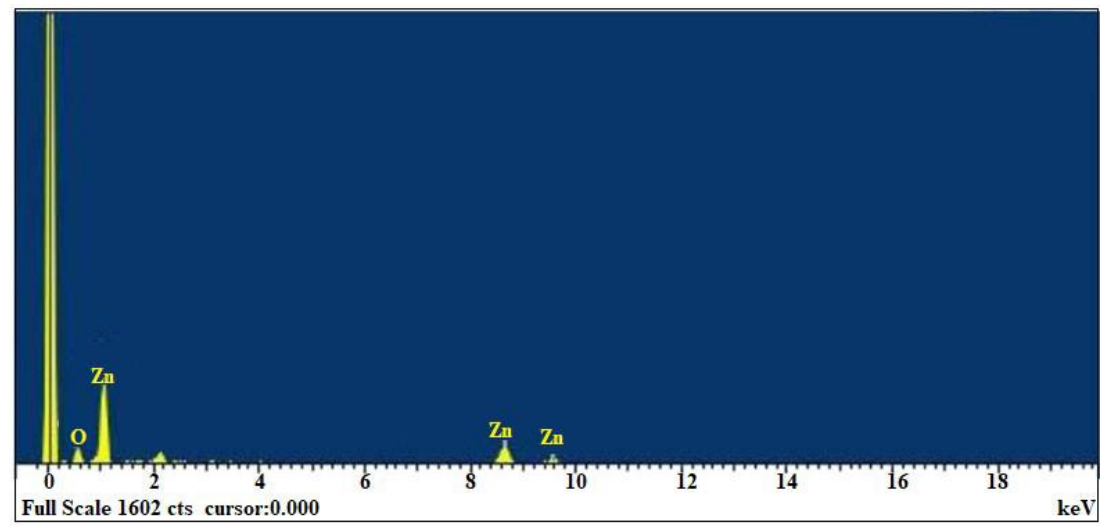

Figure2b: EDX spectra of ZnNPs calcined at $600^{\circ} \mathrm{C}$ 3.3

Table 1: Serum Immunoglobulins (Ig), hemoglobin level and serum proteins in patients and controls in acute Toxoplasmosis before interaction with $\mathrm{ZnO}$ nanoparticles

\begin{tabular}{|c|c|c|c|c|}
\hline \multirow{2}{*}{ Parameter tested } & Tested group & Tested No's & Mean \pm SD & p Value \\
\hline \multirow{2}{*}{ IgA } & Patients & 25 & $220.67 \pm 12.16$ & 0.194 \\
\cline { 2 - 6 } & Control & 20 & $97.6 \pm 22.34$ & 0.237 \\
\hline \multirow{2}{*}{ IgM } & Patients & 25 & $267.08 \pm 10.36$ & 0.289 \\
\cline { 2 - 6 } & Control & 20 & $167.31 \pm 7.61$ & 0.323 \\
\hline \multirow{2}{*}{ IgG } & Patients & 25 & $1364.07 \pm 6.92$ & 0.395 \\
\cline { 2 - 6 } & Control & 20 & $1401.07 \pm 2.37$ & 0.481 \\
\hline \multirow{2}{*}{ Hemoglobin (g/d) } & Patients & 25 & $9.14 \pm 1.24$ & 0.477 \\
\cline { 2 - 6 } & Control & 20 & $9.64 \pm 1.62$ & 0.481 \\
\hline
\end{tabular}




\begin{tabular}{|c|c|c|c|c|}
\hline \multirow{2}{*}{ Total Protein (g/dl) } & Patients & 25 & $6.07 \pm 2.67$ & 0.486 \\
\hline & Control & 20 & $5.97 \pm 1.66$ & 0.491 \\
\hline \multirow{2}{*}{ Albumin (g/dl) } & Patients & 25 & $4.67 \pm 2.02$ & 0.496 \\
\hline & Control & 20 & $4.06 \pm 1.68$ & 0.417 \\
\hline \multirow{2}{*}{ Globulin (g/dl) } & Patients & 25 & $2.07 \pm 1.80$ & 0.350 \\
\hline & Control & 20 & $2.02 \pm 1.67$ & 0.294 \\
\hline \multirow{2}{*}{ Protease activity ( $\square \mathrm{mol} / \mathrm{L}$ ) } & Patients & 25 & $684.27 \pm 61.37$ & 0.247 \\
\hline & Control & 20 & $651.33 \pm 50.63$ & 0.207 \\
\hline
\end{tabular}

Table 2: Mean concentration of IN $\gamma$ in $\mathrm{pg} / \mathrm{ml}$ in Healthy persons and patients treated with ZnNPs after 4 days

\begin{tabular}{|c|c|c|}
\hline Group Name & Healthy persons & $\begin{array}{c}\text { ZnNPs } \\
\text { Immunized group }\end{array}$ \\
\hline Concentration & 98.5 & 398 \\
\hline
\end{tabular}

\subsection{DISCUSSION}

Epidemiological surveys have suggested that $T$. gondii infection has a wide distribution. Infection of up to onethird of the world's population with $T$. gondii makes finding a safe and effective drug a great success [14]. Despite the fact that a variety of approaches have been developed in an effort to find an efficient and well-tolerated therapeutic regimen, the standard therapy is still hampered by severe adverse effects. In the search for new strategies that overcome the drawbacks of previous treatment regimens, NPs find its way as trial agents against toxoplasmosis. To our knowledge, the current research is the first evaluating ZnNPs as prophylactic and therapeutic agents against experimental toxoplasmosis. NPs have been used widely in previous studies as vehicles to deliver drugs or vaccines, to improve their therapeutic efficacy. Some of the studies have utilized NPs as a mean of treatment [15]. Curcumin, CS and AgNPs have been used in experimental treatment of giardiasis. AgNPs and the combined ZnNPs provided the best results. Furthermore, gold nanosphere/antibody conjugateswere tried successfully as treatment of experimental toxoplasmosis. IFN- $\gamma$ is a major cytokine that is critical for host resistance to abroad range of intracellular pathogens. Production of IFN-c by naturalkiller and T-cells is initiated by the recognition of pathogens by Toll-like receptors (TLRs) [16]. Hence, being a chief immune mediator, IFN- $\gamma$ was mandatory to be measured. Inthe present study, IFN- $\gamma$ level was increased following the Toxoplasma infection. However, following administration of ZnNPs, the highest level of IFN- $\gamma$ was achieved as a result of their enhancement of immunity. This was more pronounced in the patients treated by ZnNPs (Table2) .Our results were in accordance with Chen et al. (2013) [17] who reported that a strong cellular immune response was elicited during toxoplasmosis, showing significant 
production of IFN- $\gamma$ and IL-2 associated withTh1 type response. Furthermore, $\mathrm{Xu}$ et al. (2012) [18] stated that AgNPs are potent enhancer to the immune system. They have significant adjuvant effect and they elicit both Th1- and Th2-basedimmune responses. Also, they recruit leukocytes and increase cytokines levels (TNF-a and IFN$\gamma)$ in abdominal cavity and up-regulate the MHC II molecules expression of peritoneal macrophages. Thus, it can be concluded that ZnNPs showed promising results IFN$\gamma$ concentration, with statistically significant agreement between the results of all tests (Table 1). The increase in IFN- $\gamma$ concentration in response to Ag NPs strongly clarifies the results of reduction in the parasite burden in tissues.

\subsection{CONCLUSION}

Toxoplasmosis is usually considered a benign and self-limiting illness, late and permanent lesions may occur, such as T. gondii. Consequently, acute cases may need to be treated and followed up, in order to minimize the risks of such lesions. Medical staff must then be alert to this infection and its consequences, even after acute infection and remission. Therefore, the results presented in this study showed that ZnNPs are promising drugs to eliminate the parasite. The low dose used their obtained high protection, thus reducing the adverse side effects and toxicity.

\section{REFERENCES}

[1] Moghimi SM, Farhangrazi ZS, Nanoparticles in medicine: nanoparticle engineering for macrophage targeting and nanoparticles that avoid macrophage recognition. In: Boraschi D, Duschl A (eds) Nanoparticles and the immune system: safety and effects. Academic Press, London, 2013, pp 77-89

[2] Nicolle C., Manceaux L. Sur un protozoaire nouveau du gondi. Arch Inst Pasteur Tunis 2, 1909, 97-103.

[3] SIN YEW WONG, et al. Role of Specific Immunoglobulin $E$ in Diagnosis of Acute Toxoplasma Infection and Toxoplasmosis, Journal of Clinical Microbiology, Nov. 1993, p. 2952-2959 0095$1137 / 93 / 112952-08 \$ 02.00 / 0$

[4] Abaza SM. Applications of nanomedicine in parasitic diseases. Parasitol United J 2016;9,1-6

[5] Akerman ME, Chan WC, Laakkonen P, Bhatia, SN, Ruoslahti E. Proc. Natl. Acad. Sci. USA. 2002, 99, 12617

[6] Wang H, Lei C, Li J, Wu Z, Shen $\mathrm{G}, \mathrm{Yu}$ R. A piezoelectric immunoagglutination assay for Toxoplasma gondii antibodies using 
gold nanoparticles. Biosens

Bioelectron 2004, 19,701-709

[7] Hegazy S, Farid A, Rabae I, ElAmir A. Novel IMB-ELISA assay for rapid diagnosis of human toxoplasmosis using SAG1 antigen. Jpn J Infect Dis 2015, 68,474-480.

[8] Gaafar MR, Mady RF, Diab RG, Shalaby TI. Chitosan and Zinc nanoparticles: promising antitoxoplasma agents. Exp Parasitol 2014, 143,30-38.

[9] Zolnik BS, González-Fernández A, Sadrieh N, Dobrovolskaia MA. Nanoparticles and the immune system. Endocrinology 151(3), 2010,458-65

[10] Kononenko V, Narat M, Drobne D. Nanoparticle interaction with the immune system. Arh Hig Rada Toksikol 66(2), 2015, 97-108

[11] Dobrovolskaia MA, Shurin M, Shvedova AA. Current understanding of interactions between nanoparticles and the immune system. Toxicol Appl Pharmacol 299, 2016,78-89

[12] Kumar, S.S., Venkateswarlu, P., Rao, V.R. et al. Synthesis, characterization and optical properties of zinc oxide nanoparticles, Int Nano Lett 3, 2013, 30. https://doi.org/10.1186/2228-5326$3-30$

[13] Banwell CN, McCash EM, Fundamentals of molecular spectroscopy (4thedn), McGrawHill International, UK.1999.

[14] Tenter, A.M., Heckeroth, A.R., Weiss, L.M. Toxoplasma gondii: from animals to humans. International Journal of Parasitology, v.30, 2000, p.12171258 ,

[15] Sin Yew Wong, et al. Role of Specific Immunoglobulin $\mathrm{E}$ in Diagnosis of Acute Toxoplasma Infection and Toxoplasmosis, Journal Of Clinical Microbiology, Nov. 1993, p. 2952-2959 0095$1137 / 93 / 112952-08 \$ 02.00 / 0$

[16] Zolnik BS, González-Fernández A, Sadrieh N, Dobrovolskaia MA. Nanoparticles and the immune system. Endocrinology 151(3), 2010,458-65

[17] Wang L, Cheng HW, Huang KQ, $\mathrm{Xu} Y \mathrm{H}, \mathrm{Li} \mathrm{YN}, \mathrm{Du}$, et al. Toxoplasma gondii prevalence in food animals and rodents in different regions of China, isolation, genotyping and mouse pathogenicity. Parasit Vectors. 6, 2013,273. doi: 10.1186/1756-33056-273. 
[18] Xu X, Liu T, Zhang A, Huo X, Luo Q, Chen Z, et al. Reactive oxygen species-triggered trophoblast apoptosis is initiated by endoplasmic reticulum stress via activation of caspase-12, CHOP, and the JNK pathway in Toxoplasma gondii infection in mice. Infect Immun. 80, 2012, 2121-32. doi: 10.1128/IAI.0629511. 